\title{
RESEARCH ON MAINTAINING THE QUALITY OF TWO HYBRIDS OF BELL PEPPERS AFTER HARVEST
}

\author{
Sándor Rózsa ${ }^{1, *}$, Dănuț-Nicolae Măniuțiu ${ }^{1}$, Gheorghe Poșta ${ }^{2}$, Tincuța-Marta Gocan ${ }^{1}$, Vasile Lazăr ${ }^{1}$ \\ ${ }^{1}$ University of Agricultural Sciences and Veterinary Medicine Cluj-Napoca, Romania \\ ${ }^{2}$ Banat University of Agricultural Sciences and Veterinary Medicine "King Mihai I of Romania" Timişoara, Romania

\begin{abstract}
The importance of bell peppers and its share in the culture has increased greatly in recent years, due to the intensification of demand for this product on the market. In the technology of capitalization of fresh bell peppers, the achievement of an appropriate technological flow requires many specific technical and organizational specifications. At the same time, it is necessary to maintain the quality of the peppers during different transport periods, in normal or refrigerated conditions. In the technological flow of capitalizing on bell peppers, the transit period can be extended depending on the hybrid by 7-10 days in uncooled spaces and with 20-32 days in cooled spaces, by covering the products packed in boxes with polyethylene foil to achieve a relative humidity of almost $98 \%$. Covering the boxes with polyethylene foil reduces weight loss during transport with $4.57 \%$ in uncooled spaces and with $1.29 \%$ in refrigerated spaces. In 30 days of storage, the content of vitamin C in the Belladonna F1 hybrid decreased by $24 \mathrm{mg}$ and with $21 \mathrm{mg}$ in the Blondy F1 hybrid.
\end{abstract}

Keywords: bell peppers, polyethylene foil, quality, technological flow.

\section{INTRODUCTION}

Among the cultivated vegetable species, pepper (Capsicum annuиm L.) occupies an important place, having many uses (Lownds et al., 1994). Pepper fruits can be eaten fresh, which is of particular importance, due to the fact that vitamins are used entirely by the human body (Soltani et al., 2016). Pepper fruits are used in the preparation of a very wide range of dishes and are suitable for processing in the canning industry (Maria et al., 2010).

The chemical composition of pepper fruits is very complex (Yekula et al., 2013). The content of vitamin $\mathrm{C}$ depends on the degree of maturity, the size of the fruit and their conditioning immediately after harvest (Ilic et al., 2012).

The importance of bell peppers and its share in the culture has increased greatly in recent years, due to the intensification of demand for this product on the market (Antoniali et al., 2007; Bayoumi, 2008). The biological peculiarities of the plant give the peppers a pronounced seasonality, which the production and capitalization technologies have the task of reducing in order to ensure their presence in the assortment of vegetables throughout the year (Rao et al., 2011).

In the technology of capitalization of fresh bell peppers, the achievement of an appropriate technological flow requires many specific technical and organizational specifications (Chitravathi et al., 2015). 


\section{Current Trends in Natural Sciences}

Vol. 9, Issue 18, pp. 47-51, 2020

https://doi.org/10.47068/ctns.2020.v9i18.007

At the same time, it is necessary to maintain the quality of the peppers during different transport periods, in normal or refrigerated conditions (Opara and Mditshwa, 2013).

Given the requirements of bell peppers for temperature and especially for atmospheric humidity, in order to maintain the quality of bell peppers after harvest, it was considered necessary to study different conditioning conditions in the pedoclimatic conditions in Cluj-Napoca and storage of fat peppers in uncooled and refrigerated areas.

\section{MATERIALS AND METHODS}

Belladona F1 hybrids from Seminis and Blondy F1 from Syngenta grown in solariums were used in the experiments.

Belladonna F1 is a hybrid of bell pepper that has a high percentage of fruit with 4 lobes, very firm and with a thick pulp, about 6-7 $\mathrm{mm}$. The fruits are easy to pick, the average weigh $160-200 \mathrm{~g}$ and are $9-10 \mathrm{~cm}$ long and $8-9 \mathrm{~cm}$ in diameter (Figure 1).

Blondy F1 is a hybrid of early yellow blocky bell pepper, intended for cultivation in solariums and fields. The plants have high production potential of superior quality. The fruits have 3-4 lobes, weigh up to 250 grams and bright yellow color at physiological maturity. The fruits are $10 \mathrm{~cm}$ long and $10 \mathrm{~cm}$ in diameter, with firmness and a smooth appearance (Figure 2).

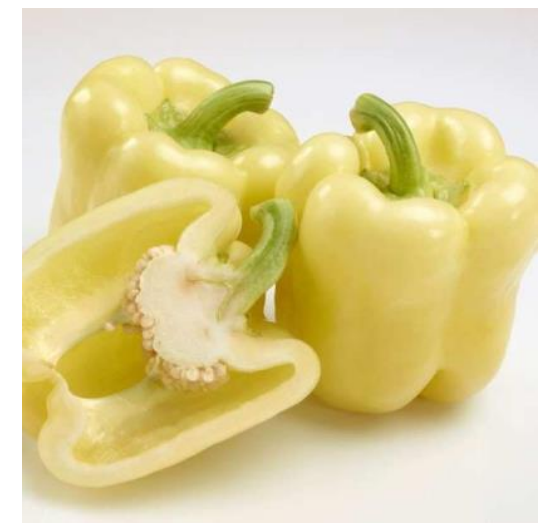

Figure 1. Belladonna F1

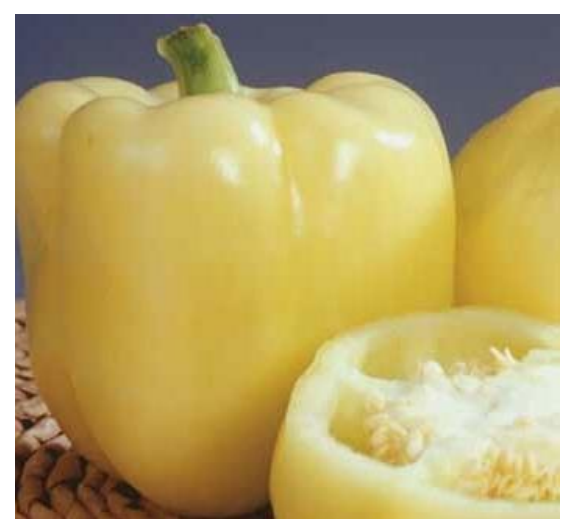

Figure 2. Blondy F1

In order to store, the harvested products were hand-packaged, and in experience only extra quality was used.

The peppers were packed in PVC boxes with a capacity of $4 \mathrm{~kg}$, which were packaged for storage as follows:

V1 - sort and pack in crates;

V2 - sort, sprinkle with cold water and packed in crates;

V3 - sorted, packed in crates under $0.018 \mathrm{~mm}$ polyethylene foil.

The peppers were stored as follows:

D1 - in simple warehouses with a temperature between $20-24{ }^{\circ} \mathrm{C}$ and $70-75 \% \mathrm{RH}$;

D2 - in cold rooms with a temperature between $10-12{ }^{\circ} \mathrm{C}$ and $\mathrm{RH} 80-85 \%$.

During the study, the following characteristics were observed:

-duration of quality (marked with 9 - freshness of the field, extra quality; 7 - slight defects, reduction of gloss; 5 - visible loss of turgidity; 3 - below standard, edible only by preparation; 1 inedible); 


\section{Current Trends in Natural Sciences}

Vol. 9, Issue 18, pp. 47-51, 2020

https://doi.org/10.47068/ctns.2020.v9i18.007

-dynamics of quantitative losses and qualitative depreciation; -dynamics of chemical composition.

\section{RESULTS AND DISCUSSIONS}

The duration of quality maintenance in the studied bell pepper hybrids was expressed by the number of days from harvest until the product has passed from the field freshness phase (note 9), to a less good quality grade (note 7) when the first signs of loss of freshness such as reduced glossiness and turgidity appear. The transition from grade 9 to 7 is the threshold after which the product is downgraded, and its capitalization will be made to lower quality categories.

Following the data in Figure 3 and 4, it appears that in both hybrids, in all experimental variants, the refrigerated space favours a longer duration of maintaining the freshness of the fruit, 16 days for the Belladonna F1 hybrid and 13 days for the Blondy F1 hybrid, compared to environmental preservation, where maintaining quality is reduced to 3 days.

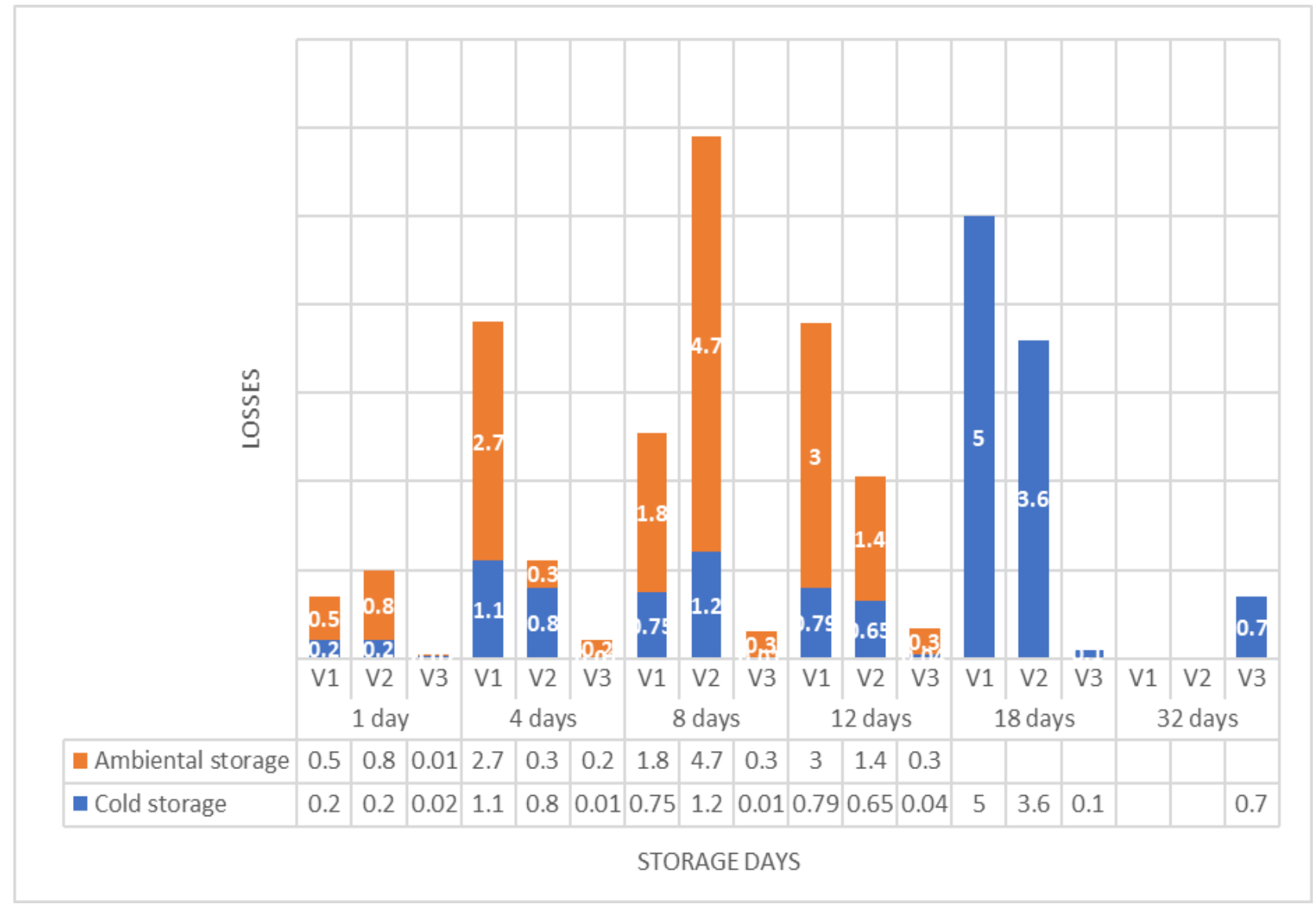

Figure 3. The duration of quality maintenance at Belladonna F1 hybrid 


\section{Current Trends in Natural Sciences}

Vol. 9, Issue 18, pp. 47-51, 2020

https://doi.org/10.47068/ctns.2020.v9i18.007

Current Trends in Natural Sciences (on-line)

ISSN: 2284-953X

Current Trends in Natural Sciences (CD-Rom)

ISSN: 2284-9521

ISSN-L: 2284-9521

ISSN-L: 2284-9521

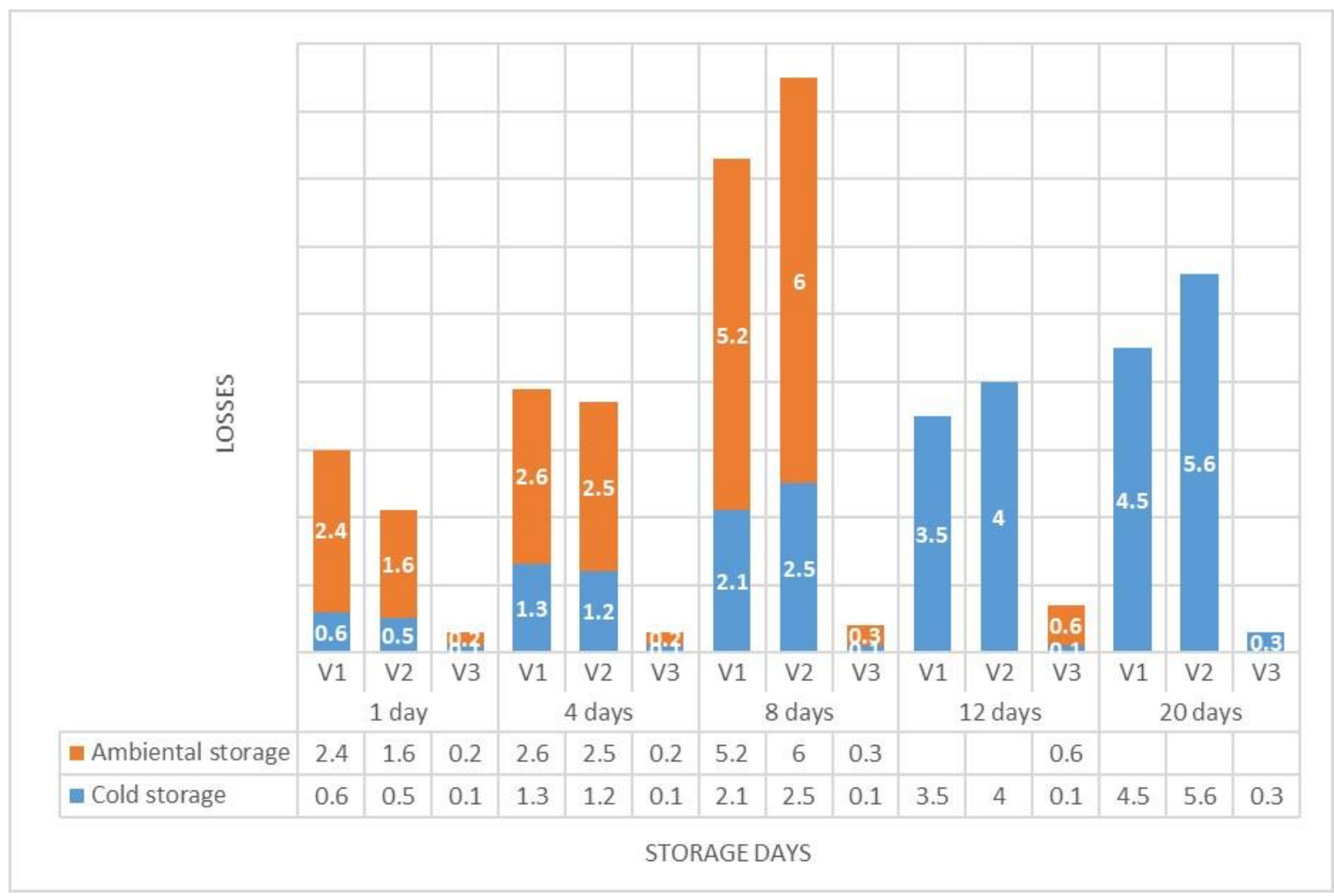

Figure 4. The duration of quality maintenance at Blondy F1 hybrid

Comparing the behaviour of the peppers from the 3 variants, in both hybrids, regardless of the storage place, in an uncooled or refrigerated space, the maximum duration of quality maintenance is achieved in variant $\mathrm{V} 3$, under the polyethylene foil:

-in ambient conditions 10 days at $20-24{ }^{\circ} \mathrm{C}$ and relative humidity close to $98 \%$,

-in refrigerated conditions at $10-12{ }^{\circ} \mathrm{C}$ and relative humidity close to $98 \%, 20$ days for Blondy F1 hybrid and 32 days for Belladonna $\mathrm{F} 1$ hybrid.

The extension of the quality maintenance time for peppers under the polyethylene foil is due to the higher and constant relative humidity of the air under the foil, compared to the environmental environment in the warehouse.

The results we obtained confirm the existing data in the literature on the high demands of the air against atmospheric humidity, compared to other species of vegetables in the Solanaceae family. Figures 3 and 4 also show the weight loss recorded during storage for each experimental variant. From the first day after harvesting, it was found that the weight losses from peppers in the uncooled space are higher than those recorded in the refrigerated space.

Thus, if we consider a transit period from manufacturer to distributor of 4 days, the Belladonna F1 hybrid recorded weight losses between $0.2-1.8 \%$ at temperatures of $20-24{ }^{\circ} \mathrm{C}$, and relative air humidity of $70-75 \%$ and $0.01-1.1 \%$ when stored at $10-12{ }^{\circ} \mathrm{C}$ and $\mathrm{RH} 80-85 \%$. The data obtained are close to those presented by (Opara and Mditshwa, 2013).

The Blondy F1 Hybrid recorded in 4 days of storage a weight loss between $0.2-2.6 \%$ when stored at temperatures of $20-24{ }^{\circ} \mathrm{C}$, and relative air humidity of $70-75 \%$ and $0.01-1.3 \%$ when stored at $10-12$ 
Vol. 9, Issue 18, pp. 47-51, 2020

https://doi.org/10.47068/ctns.2020.v9i18.007

${ }^{\circ} \mathrm{C}$ and $\mathrm{RH}$ 80-85\% air humidity. Also, in the case of this hybrid, the data obtained are close to those mentioned in the literature by other authors (Yekula et al., 2013).

More significant quality impairments were found in both hybrids, after 18 days of storage at room temperature.

Comparing the variants in terms of wight losses, it is obvious that in both environmental conditions the lowest values were recorded in the refrigerator for peppers in variants V3 (covered with foil), where the atmosphere saturated with water vapor prevented its evaporation from fruit.

Following the evolution of the chemical composition of these hybrids during storage, under the given experimental conditions it is found that in 30 days of storage, the content of vitamin $\mathrm{C}$ in the Belladonna F1 hybrid decreased by $24 \mathrm{mg}$ and with $21 \mathrm{mg}$ in the Blondy F1 hybrid.

\section{CONCLUSIONS}

In the technological flow of capitalizing on bell peppers, the transit period can be extended depending on the hybrid by 7-10 days in uncooled spaces and with 20-32 days in cooled spaces, by covering the products packed in boxes with polyethylene foil to achieve a relative humidity of almost $98 \%$.

Covering the boxes with polyethylene foil reduces weight loss during transport with $4.57 \%$ in uncooled spaces and with $1.29 \%$ in refrigerated spaces.

In 30 days of storage, the content of vitamin $\mathrm{C}$ in the Belladonna F1 hybrid decreased by $24 \mathrm{mg}$ and with $21 \mathrm{mg}$ in the Blondy F1 hybrid.

\section{REFERENCES}

Antoniali, S., Paulo, M., Ana-Maria, M., Rogerio, T., Juliana, S. (2007). Physicochemical characterization of 'zarco hs' yellow bell pepper for different ripeness stages. J. Sci. Food Agric. 64, 19-22.

Bayoumi, Y. (2008). Improvement of postharvest keeping quality of white pepper fruits (Capsicum annuum L.) by hydrogen peroxide treatment under storage conditions. Acta Biologica Szegediensis, 52, 7-15.

Chitravathi, K., Chauhan, O.P., Raju, P.S. (2015). Influence of modified atmospheric packaging on shelf life of green chillies. Food Packaging and Shelf Life 4, 1-9.

Ilic, S., Trajkovic, R., Pavlovic, R., Alkalai-Tuvia, S., Perzelan, Y., Fallik, E. (2012). Effect of heat treatment and individual shrink packaging on quality and nutritional value of bell pepper stored at suboptimal temperature. Int. J. Food Sci.Technol. 47, 83-90.

Lownds, N.K., Banaras, M., Bosland, P.W. (1994). Postharvest water loss and storage quality of nine pepper (capsicum) cultivars. HortScience 29, 191-3.

Maria, S., Zapata, P., Castillo, S., Guillen, F., Martinez-Romero, D. (2010). Antioxidant and nutritive constituents during sweet pepper development and ripening are enhanced by nitrophenolate treatments. J. Food Chem. 118, 497-503.

Opara, U.L., Mditshwa, A. (2013). A review on the role of packaging in securing food system: Adding value to food products and reducing losses and waste. African Journal of Agricultural Research 8 (2), 621-630.

Rao, R., Gol, B., Shah, K. (2011). Effect of postharvest treatments and storage temperatures on the quality and shelf life of sweet pepper. Sci. Hortic. 132, 18-26.

Soltani, M., Alimardani, R., Mobli, H., Mohtasebi, S.S. (2016). Modified atmospheric packaging: A progressive technology for shelf life extension of fruits and vegetables. Journal of Applied Packaging Research 8, 33-59.

Yekula, B., Srihari, D., Babu, J.D. (2013). Extension of gharkin shelf life through the use of reduced temperature and poly ethylene packaging. Vegetable Science 40 (2), 174-177. 